This is the author's final, peer-reviewed manuscript as accepted for publication. The publisher-formatted version may be available through the publisher's web site or your institution's library.

\title{
Creating new partnerships: an examination of two collaborative, grant-funded digitization projects
}

Jenny Oleen and Livia Olsen

\section{How to cite this manuscript}

If you make reference to this version of the manuscript, use the following information:

Oleen, J., \& Olsen, L. (2011). Creating new partnerships: An examination of two collaborative, grant-funded digitization projects. Retrieved from http://krex.ksu.edu

\section{Published Version Information}

Citation: Oleen, J., \& Olsen, L. (2011). Creating new partnerships: An examination of two collaborative, grant-funded digitization projects. Journal of Agricultural \& Food Information, 12(3-4), 370-376.

Copyright: Copyright @ Taylor \& Francis Group, LLC

Digital Object Identifier (DOI): doi: 10.1080/10496505.2011.619380

Publisher's Link: http://www.tandfonline.com/doi/abs/10.1080/10496505.2011.619380

This item was retrieved from the K-State Research Exchange (K-REx), the institutional repository of Kansas State University. K-REx is available at http://krex.ksu.edu 


\title{
Creating New Partnerships: An Examination of Two Collaborative, Grant-funded Digitization Projects
}

\author{
JENNY OLEEN and LIVIA OLSEN \\ Kansas State University Libraries, Kansas State University, Manhattan, Kansas, USA
}

Many agriculture professors are also avid photographers. Throughout their careers, they photograph the unique, the mundane, and the fantastic. Their photographs and slides range from beautiful roses and champion bulls to wheat covered in rust and sickly sows. During their academic years, they use the slides for class lectures, at conferences, and at presentations to the public. Many professors and researchers also collect print materials, amassing huge collections of pamphlets, research reports and books. These items, though old or out of print, often are unique and have great historic value. They document the progress and results of a professor's research and academic career. What happens to these valuable materials upon a professor's retirement? Will they languish in a departmental library? Will they be lost in an attic? Will they be discarded? Hopefully not. These materials represent part of that professor's knowledge, acquired over a lifetime. They are a valuable source of information for future generations.

Two grant-funded, collaborative projects, conducted at Kansas State University, endeavored to remedy this problem. The first project involved digitizing natural history publications which are now available on the Internet through the web portal BiodlS (http://biodis.k-state.edu/), Kansas State University's Biodiversity Information System. The second involved digitizing $35 \mathrm{~mm}$ slides of grain sorghum (Sorghum bicolor) disease images slides that were originally captured by Dr. Larry Claflin, a plant pathology professor. Dr. Claflin is an internationally recognized expert on grain sorghum diseases and was nearing retirement when he approached the library about preserving approximately 450 grain sorghum disease slides. Both projects were collaborations between librarians and academic faculty.

KEYTERMS: Digital Preservation, Biodiversity Information System, Digitization, grain sorghum

\section{HISTORIES OF THE PROJECTS}

The earth is dominated by two groups of organisms--insects and plants. These are represented at Kansas State University by two separate natural history collections: the Kansas State University Herbarium and the Museum of Entomological and Prairie Arthropod Research. These are large, active research museums whose collections are noted for their historically significant holdings of biological specimens from the Great Plains region. Data from these collections is fundamental to biodiversity research and understanding biological and climatological change.

Address correspondence to Jenny Oleen or Livia Olsen, K-State Libraries, 137 Hale Library, 1100 Mid-Campus Drive, Manhattan, KS 66506, USA. Email: livia@k-state.edu 
These museums are more than just their historical specimen collections, as both include significant taxonomic libraries containing a wealth of print literature related to their areas of study, much of which is out of print or otherwise difficult to find. As natural history museums digitize their specimens and related records to make them available online, less emphasis is placed on the taxonomic libraries these museums house. As a result, taxonomic libraries such as these are often overlooked and inaccessible to users working remotely. At Kansas State University such collections at the two museums contained approximately 34,000 print monographs comprising nearly 431 linear feet of documents ranging from reprints to serials to dissertations to federal publications and more. For the first project, in order to increase access to both the specimen and literature collections, the Kansas State University Herbarium, the Museum of Entomological and Prairie Arthropod Research, and Kansas State University Libraries collaborated to receive a Targeted Excellence Grant from the Kansas State University Provost's office for the Biodls project.

The second project was also grant funded. Dr. Larry Claflin was a plant pathologist at Kansas State University from 1975 to 2006. During the course of his academic career he traveled widely in Africa, Asia ${ }_{\perp}$ and North America, studying and recording the diseases of various crops. He became particularly noted as an expert in grain sorghum diseases. During Dr. Claflin's travels, he took many pictures, in the form of $35 \mathrm{~mm}$ transparencies, of the plants and their diseases. As Dr. Claflin neared retirement he wanted to find a home for his grain sorghum slides. Kansas State University librarians Mike Haddock and Mohan Ramaswamy worked with Dr. Claflin to craft a project that would preserve the slides and make them publicly available for others to view and learn from the grain sorghum images.

They eventually decided to digitize the slides and applied for a National Agricultural Library cooperative agreement to help fund the project. The project, titled "A Grain Sorghum Disease Image Collection: Optimizing the Digitization Protocol”, was accepted for cooperative agreement

funding ${ }_{2}$ and the digitization of grain sorghum disease images from across the world, including images of grain sorghum diseases that are uncommon in the United States, was undertaken. Many of the images were captured in Sudan, where grain sorghum is a very important food crop. Dr. Claflin selected slides from his collection to illustrate the effects of a wide variety of

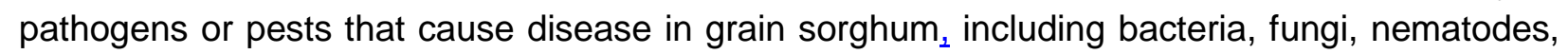
and parasitic plant pests. Many of the slides were 30 to 40 years old.

\section{DIGITIZATION OF MATERIALS}

Digitization workflow documentation for the grain sorghum digitization project was created by the principal investigators, Mike Haddock and Mohan Ramaswamy, to insure consistency in the results. The $35 \mathrm{~mm}$ slides were scanned on a Nikon slide scanner as TIFF files. Some slides 
had deteriorated due to their age ${ }_{2}$ so following scanning a color correction and image quality procedure was followed using Adobe Photoshop CS.

Dr. Claflin selected the slides for digitization, examining their potential utility in helping researchers and professionals identify specific diseases in the field. He then provided the metadata for all of the slides in a spreadsheet format utilizing a unique identifier for each slide. The metadata fields, with the exception of the unique identifier, corresponded to the fields used in the Plant Diagnostic Information System (PDIS) Image Library system. The PDIS is an online application shared by researchers and professionals in agriculture from across the nation. Once the images and metadata were entered and uploaded into the PDIS system they underwent a review procedure where Dr. Claflin accepted or rejected each image. Rejected images were reentered into the PDIS after editing the metadata or correcting the image. Once approved by Dr. Claflin the images were made publically accessible on the Internet. A protocol was also created to aid future users of the PDIS Image Library in uploading images to the library.

As a part of the Target Excellence collaboration with the natural history museums, monographs were selected for digitization based on historical significance, continued use, and importance to the Great Plains region [insert image DSC03058bw.tif]. The Bibliographical Center for Research's (BCR) CDP (Collaborative Digitization Program) Digital Imaging Best Practices were used as standards in the monographs for the digitization project. Master TIFF images were saved, while copies were touched up in Adobe Photoshop. Scans were then processed using ABBYY Fine Reader, an optical character recognition software. ABBYY was used to save the documents as PDF files, which were made available through the BiodIS web site (http://www.biodis.k-state.edu).

The grant team encountered problems related to the digitization portion of the project. One such problem was related to the size of the final PDF documents uploaded to the BiodIS site. Depending on the size of the monographs initially digitized, these PDF files could range from just under $15 \mathrm{MB}$ to well over $150 \mathrm{MB}$. Users interested in downloading the files over an ethernet connection would not likely have a problem with the documents, though they may take longer than a typical PDF download because of their large size. But as a Land Grant University, part of the mission of both Kansas State University and of the project is to disseminate information to end users - farmers and ranchers in the state of Kansas. While some of these users may have access to high speed internet, others are still using dial-up connections that cannot readily download files as large as these.

After investigating several options, the project chose to try ContentDM, a product K-State Libraries had also been investigating to use for digitized items from the archives. With ContentDM the team could deliver the monographs as compound objects, where users could view the item page by page without downloading the entire digitized piece. The team also investigated widgets with page turning functionality, so users could page through the 
monograph in their internet browser. From this investigation, the team selected software from 3D Issue to create a page turning display for each of the PDF files available through BiodIS. While this interface is more user friendly, it still requires the download of the PDF file for the page turning software to work. However, by offering multiple options, BiodIS can deliver the digitized content to a variety of end users regardless of their technological capabilities.

\section{OUTCOMES}

One outcome of the Targeted Excellence Grant was the creation of the Biodiversity Information System web site, http://biodis.k-state.edu. This web site allowed team members to make the catalogs of specimens from each of the museums available alongside each other and the monographs that were digitized. This one-stop-shopping nature of the web site allows for greater integration of research across the disciplines. By having the systematic keys readily available for users of the web site, BiodIS endeavors to provide all the information a researcher might need in one place.

To provide the customized interface for users, the team decided to create and locally host the web site instead of turning to an outside host. While initial plans included creating the platform for the website, the decision was made to combine platforms already available. Using WordPress, a blogging software which was used as a content management system, to power the site and Silver Collection, a commercially developed web portal for biological collections, to deliver the museum catalogs, the team was able to create a website that had the tools needed without recreating tools that were already available. As a part of this system, the team created a Digital Resources page within the WordPress site to deliver the documents scanned for the project.

Likewise, the digitized grain sorghum disease images give people attempting to identify grain sorghum diseases access to an online resource that they can utilize. The PDIS Image Library allowed users to download images in several formats: PNG, JPEG, BMP and TIFF. Information, including scientific and a common names of the plant and the pathogen or pest are embedded in the download so that the user would have that information in one place if the image is useful to them.

While the BiodIS project developed its own web site, utilizing multiple platforms for items digitized during the project, the grain sorghum image project utilized a pre-existing platform, the PDIS Image Library, to present the results of the project. Though developing a web site for BiodlS was challenging and time consuming, it gave the BiodlS project team full control over how the digitized content was archived and displayed. The lack of control over the final product has caused problems for the grain sorghum disease image project. Sadly, the PDIS Image Library system became inactive, due to technical complications of transferring to a new system, sometime during the spring of 2010. All images stored in the image library are no longer 
accessible via the Internet, defeating one of the original purposes of the project, the dissemination of the images so that they might be better used. It is unknown when the PDIS Image Library will again be available. In the meantime, the images are backed up on CDs and on a hard drive in the library. Perhaps in the future, Kansas State University Libraries will explore alternatives for making the grain sorghum disease image collection available on the Internet if it is determined that the PDIS Image Library's functionality will not return.

\section{CONCLUSION}

Digital images are now the norm. Rather than presenting $35 \mathrm{~mm}$ slide shows, educators utilize a computer and digital projector to present lectures and images. In lieu of pulling books from library shelves, researchers download articles and e-books. Scanning slides and print materials is a way to insure that future students and researchers use these unique and important materials. As these two projects have shown, digitizing these materials also creates an opportunity to make them accessible on the Internet for anyone interested in learning about plants, insects, or plant diseases. By digitizing the systematic keys for the BiodIS project, these out of print monographs are now more widely available to researchers studying plants and insects in the Great Plains. Digitizing slides of grain sorghum disease creates an online resource for diagnosing plant diseases. These items will not just sit in a university archive where only a few people a year may go to the trouble of viewing them. Digital versions of materials are also back-ups in the event that the originals are destroyed.

As collaborative projects such as these show, educators are interested in preserving photos, slides, and documents digitally, but they may not have the time or the resources to do so. Projects such as the BiodIS and Grain Sorghum Disease Image projects help to alleviate the time constraints academic faculty encounter in preserving their work and serve as a model for future projects. Academic librarians can encourage them to work within their departments or create partnerships with librarians and archivists to pursue funding that will enable them to preserve their valuable items digitally. Different groups have different talents and resources. By bringing together three disparate groups, the BiodlS project was able to put together an interdisciplinary archive that integrates botanical and entomological information. The key to preserving the grain sorghum images was cooperation between a faculty member and librarians. Luckily, many projects of this sort are already underway to preserve unique, valuable images and print resources. Future researchers, students, and the general public will be able view and learn from these digitized images and documents. 